\title{
A ética médica sob o viés da bioética: o exercício moral da cirurgia
}

\section{Medical ethics under the bioethics' point of view: the moral surgical practice}

\author{
Eliana Maria Restum Antonio, tCBC-RJ'; Tereza Maria Pereira Fontes²
}

\author{
R E S U M O
}

\begin{abstract}
O exercício profissional da medicina atual tem uma forte abordagem biológica, devido à crescente especialização da ciência médica. Com frequência, a ciência, por si só, não ajuda a enfrentar e resolver uma situação particular de um profissional médico, e este é o lugar onde as ciências humanas, sociais e, especialmente as outras disciplinas, como a Bioética, podem dar uma abordagem mais humana e socialista, ao estudar sistematicamente a conduta humana no campo das ciências da vida e da saúde, através da luz dos valores e princípios morais. Como parte deste estudo, o segmento que está limitado à análise dos conflitos éticos decorrentes da prática da medicina e da assistência ao paciente, é conhecido como Ética médica. A Ética médica, no âmbito da cirurgia, compreende a integração do paciente cirúrgico com a natureza do cirurgião, influenciada pela sua formação e pelo seu treinamento, pela sua sensibilidade em identificar o que é correto. O ético não deve estar apenas no procedimento, no ato cirúrgico propriamente dito ou no que acontece em uma sala de operação ou mesmo no exercício da cirurgia como especialidade. A ética deve estar na vida e conduta do cirurgião, de forma que todos os atos profissionais e de vida devam ser eticamente válidos.
\end{abstract}

Descritores: Ética médica. Bioética. Cirurgia.

\section{INTRODUÇÃO}

No que concerne à Ética para se referir aos dilemas ou escolhas, o desenvolvimento ético existe porque há uma possibilidade de mais de uma decisão, se for devidamente fundamentada. Por isso, em todas estas considerações devemos construir alguns pressupostos básicos doutrinários, como admitir algumas semelhanças e diferenças entre as disciplinas filosóficas e "natural", "exato" ou "mensuráveis". Entre as semelhanças, temos a mesma base científica e profundidade semântica e, entre os contrastes, a incapacidade de observar estritamente e experimentalmente as disciplinas abstratas, mesmo assim, em especial a ética, não deve ser baseada em metas e objetivos específicos e concretos, mas em princípios e valores, para não perder sua essência. "Integridade sem conhecimento é fraca e inútil e o conhecimento sem integridade é perigoso e horrivel". Samuel Johnson (1709-1784)1.

"A humanidade tem uma dupla moral. Aquele que prega e pratica, e outra, que pratica mas não prega" Bertrand Russell (1872-1970)².

O que é ético é o que deve ser atingido, é o que deve ser estabelecido como padrão de conduta, que está acima de uma regra técnica apenas, ou de um procedimento estratégico. O zelo pela vida do paciente ainda que materializado em ações objetivas, na sua essência é dirigido subjetivamente por um devotamento ético que desper- ta o cuidado e a preocupação com a saúde e a vida do mesmo ${ }^{3}$.

Nesta fruição do próprio direito de viver, o Cirurgião busca o seu compromisso com o paciente que necessita de sua arte e de sua experiência na solução de cada terapêutica, para cada patologia, particular, irremediavelmente limitada à problemática de cada caso.

\section{ANTECEDENTES}

\section{1. Ética e medicina}

Tradicionalmente, o médico viu-se como um pequeno patriarca que exerce pouco controle sobre seus pacientes e exige destes, obediência e submissão (paternalismo). Para Aristóteles, o paciente é como uma criança ou um escravo, irresponsáveis, incapazes de moralidade, que não pode e não deve decidir sobre sua própria doença ${ }^{4}$. A doença tem um caráter imoral para eles. A atitude do médico para com o paciente é algo religioso. O médico é uma espécie de sacerdote. Este é o paternalismo médico que tem dominado a medicina ocidental desde o século $V$ a.C. até hoje. O médico Hipócratico e Galénico, vai se transformar no curso da modernidade, sem perder o seu caráter paternalista. Percival acredita que o paciente pode agravar-se se as suas decisões e preferências são autoritariamente canceladas. Esta doutrina é

1. Chefe da 17 Enfermaria do Hospital Geral da Santa Casa da Misericórdia do Rio de Janeiro- - RJ-BR; 2. Professora da Universidade Gama Filho/ Hospital da Piedade- Rio de Janeiro - RJ-BR. 
estabelecida em 1847, no Código da American Medical Association, e depois no Código Nacional de Ética Médica. Portanto, desde a tradição médica hipocrática, até agora, sempre se defendeu o critério ético da beneficência. Isto tem sido entendido como um paternalismo, negando a capacidade do paciente de tomar decisões, portanto, violando a sua autonomia ${ }^{5}$

O exercício profissional médico de hoje tem uma forte abordagem biológica, devido à crescente especialização da ciência médica, o que resulta em uma prática impessoal. Os doentes necessitam de cuidados de saúde integral para recuperar o seu equilíbrio emocional. Exige, portanto, um resgate humanitário no ensino médico, a criação de uma ponte entre estas duas disciplinas, garantindo que os médicos em formação possam adquirir e transformar uma atitude, para manter os direitos dos pacientes e ampliar a obtenção de uma formação humanística do médico formado nas universidades ${ }^{6}$.

O médico é confrontado com situações novas e, muitas vezes, complexas, onde a forma para resolver esta situação pode refletir uma determinada ideologia, muitas vezes, dependente de sua formação integral ao longo da sua vida e carreira, a sua decisão terá uma repercussão direta sobre o paciente e seus familiares ${ }^{7}$. Com frequência, a ciência por si só não ajuda a enfrentar e resolver uma situação particular de um profissional médico, e este é o lugar onde as ciências humanas, ciências sociais e especialmente as outras disciplinas, podem dar uma abordagem mais humana e socialista6.

Maia assinala alguns aspectos importantes da ética médica: a necessidade de dar ênfase a um enfoque humanístico para a educação médica, a necessidade de se criar a um profissional com atitude, compromissado com seu meio ambiente natural e social, a necessidade de desenvolver qualidades essenciais para o profissional da medicina, permitindo um exercício médico não apenas voltado para conquistas materiais, mas também alcance um desenvolvimento moral, científico e, até mesmo estético, com uma vocação médica, visando prioritariamente a realização plena da dignidade do homem como um ser humano ${ }^{7}$.

Santo Agostinho se destacou pois, foi o primeiro a ter um pensamento eminentemente ético, referindo-se sobretudo ao encontro da felicidade; todos os recursos devem ser concentrados na mente e no coração ${ }^{8}$. O amor é a força que o atrai: assim como os corpos físicos são atraídos para o centro da Terra. Com o seu peso, Santo Agostinho é atraído para seu centro - Deus - por amor. Daí seu criptograma: "Meu peso é o meu amor" 9 .

A importância da formação na ética médica em sua capacidade profissional, é demonstrada pelo fato de que, durante séculos, o código de ética médica limitou-se ao famoso juramento estabelecido pelo histórico médico grego Hipócrates, onde se lê: "Juro por Apolo, médico, e Panacea Hígia, a cujo testemunho apelo, que eu, com todas as minhas forças e com pleno conhecimento cumprirei completamente meu juramento... No que diz respeito à cura do doente... Considerarei sagrada minha arte e minha vida..." 10

Da mesma forma, disse Razetti "nós médicos devemos preservar a profissão dentro dos limites da dignidade e grandeza" 10

\subsection{Fundamentos e princípios da Bioética}

De origem recente, o vocábulo composto bioética, cuja etimologia dos radicais gregos que formam a palavra bios (vida) e éthos (comportamento, ética, conduta) já revela o campo de reflexão. Indubitavelmente, a palavra bioética representa uma daquelas palavras em que as pessoas se acostumam com o seu uso, mas não se preocupam muito com a definição de seu significado. Esta situação é semelhante ao que ocorre com palavras como justiça, liberdade, amor, felicidade, Deus, ética, e outras ${ }^{11}$.

Segundo Cely, a Bioética é definida como "disciplina científica que estuda os aspectos éticos da medicina e da biologia em geral, assim como a relação do homem com outros seres vivos; o estudo sistemático do comportamento humano no campo das ciências biológicas e da atenção à saúde, na medida em que esse comportamento é considerado a luz dos valores e princípios morais"10. "A bioética trabalha na afirmação da vida como um fator de convergência e de integração entre o homem e a natureza; é um reflexo basicamente em três níveis intrinsecamente relacionados à vida, a sua qualidade e sentido"12.

Bioética, em um de seus significados de maior importância, é " um estudo sistemático da conduta humana no campo das ciências da vida e da saúde, através da luz dos valores e princípios morais"13. Como parte deste estudo, o segmento que está limitado à análise dos conflitos éticos decorrentes da prática da medicina e da assistência ao paciente, é conhecido como Ética Médica ou Ética Clínica ${ }^{14}$

Segundo James Drane: "...o problema começa com a tentativa de definir o termo bioética. Pode-se definir bioética como uma disciplina nova e verdadeiramente emblemática da nossa época. Nenhuma outra disciplina ou área de estudo reflete mais fielmente a nossa contemporaneidade..." "15. "O campo da bioética abrange muitos dilemas éticos gerados pela pesquisa da ciência biológica e aplicações médicas. É uma disciplina paradigmática porque esses dilemas forçam-nos a lidar com os problemas essenciais da vida e da morte: Quem somos?, Porque estamos aqui?, O que é a família, a integridade, a identidade, o parentesco, a liberdade, o amor ou a comunidade..." 16 .

O primeiro uso do termo, um neologismo, de fato, foi feita pelo Dr. Van Raessenlaer Potter, oncologista e humanista da Universidade de Wisconsin, Estados Unidos, falecido em 07 de setembro de 2001, em Madison, também nos Estados Unidos, aos 90 anos de idade. Potter, em 1971, publicou um livro chamado "Bioética: Ponte para 
o Futuro", no qual expressa sua profunda preocupação com a interação das questões ambientais e de saúde, combinando suas idéias com as do Professor Aldo Leopold e sua "Ética da Terra". Potter afirmou que "Ciência e Ética marcham através de caminhos diferentes, mas paralelos e a Bioética deve ser a ponte que os une".

Potter lembrou que, em 1975, já havia alertado para a dicotomia entre a concepção original de bioética e dos eticistas médicos; uma preocupação com o fato de que a ética deve estar presente nos limites das observações biológicas, empíricas e experimentais, e com a necessidade de se elaborar um sistema de ética capaz de promover diretrizes para uma atuação responsável do ser humano em relação ao futuro. Potter ainda afirmava entender a bioética como uma ciência da sobrevivência humana,e pedia que se pensasse bioética como uma nova "ciência ética" que combina 'humildade", "responsabilidade" e uma competência "interdisciplinar" e "intercultural" potencializadora do senso de humanidade ${ }^{11}$.

Esta nova abordagem espalhou-se rapidamente ao redor do mundo e o governo norte americano formou a Comissão Belmont para estabelecer padrões éticos a serem seguidos pela pesquisa científica. Esta comissão apresentou seu relatório em 1978 e estabeleceu os primeiros princípios da Bioética: beneficência, autonomia e justiça, aos quais, mais tarde, Beauchamp e Childress acrescentaram outro: Não maleficência. Nos anos seguintes, a Bioética evoluiu e recebeu contribuições de vários autores, tendo sido definido três etapas principais neste processo ${ }^{17}$.

a) A primeira fase chamada de Bioética Ponte, interdisciplinar, utilizada como base para todas as abordagens na tentativa de integrar as ciências da vida, do meio ambiente, da ecologia e das ciências humanas, no estilo Potter. No entanto, sua duração não foi muito longa devido ao desenvolvimento rápido e descontrolado da tecnologia e descobertas na área da saúde;

b) Na segunda fase, conhecida como Bioética Global, o professor Potter, em 1988, reiterou as suas idéias iniciais e, o termo foi mundialmente compreendido como uma proposta para incluir todos os aspectos da vida, saúde e ecologia. O professor Tristan Engelhardt manteve o ponto de vista de que a bioética deveria continuar a ser uma proposta pluralista. Outros autores, como Alistair Campbell e Solly Benatar entenderam o termo global, não no sentido de incluir a todos, mas uma visão uniforme e consistente em termos mundiais, enquadrada no âmbito do processo de globalização que o mundo estava começando a experimentar, ou seja, eles queriam, de alguma forma, estabelecer um único paradigma filosófico para a abordagem das questões morais na área da saúde, o que poderia ser interpretado como uma nova versão do "imperialismo" 18.

c) A terceira fase começa com o lançamento pelo próprio Potter, no final de 1998, da Bioética profunda, aceitando a equiparação feita por Peter Whitehouse que aplicava a bioética ao conceito de Ecologia Profunda do filósofo norueguês Arne Naess ${ }^{19}$. Esta proposta humanizadora já estava sendo defendida por autores como André Comte-Sponville ${ }^{20}$ e reforçada pela posição da Organização Panamericana de Saúde, que, em 2001, definiu a Bioética de forma mais ampla, incluindo a vida, saúde, e ambiente, como suas áreas de reflexão ${ }^{21}$.

\section{O EXERCICIO MORAL DA CIRURGIA}

Oriundo do grego éthos - conduta, hábito ou comportamento -, o termo ética designa, em geral, a ciência da conduta. A palavra humildade, oriunda do latim humilitas, designa a virtude que nos dá o sentimento de nossa fraqueza e que informa a atitude do ser humano consciente dos seus limites. O termo responsabilidade, do inglês responsability, indica a possibilidade de prever os efeitos de um comportamento e de corrigi-lo, antes de sua realização, com base na previsão. A ética, dessa forma, exprime uma preocupação com o resultado final do comportamento ${ }^{11}$.

A ética médica, no âmbito da cirurgia, compreende a integração do paciente cirúrgico, com a natureza do cirurgião, influenciada pela sua formação e pelo seu treinamento, pela sua sensibilidade para identificar o que é certo ${ }^{22}$. A incorporação da ética na prática da medicina tem uma longa tradição que começa na Grécia clássica, o Juramento de Hipócrates, que era o referencial ético médico no Ocidente por muitos séculos, e foi continuado nos últimos tempos com a Oração Maimonides, do Século XII; os padrões éticos do Royal College of Physicians, da Inglaterra, em 1543; as normas reguladoras da prática médica no Protomedicato, de Nueva Espana, em 1628; a obra de John Gregory: Observations on the Duties and Offices of a Physician and on the Method of Prosecuting Enquiries in Philosophy, de 1770; o Código de Ética Médica do Thomas Percival, de 1806; o Código de Ética da Associação Médica Americana, em 1847, e, finalmente, os muitos documentos escritos ao longo do Século XX pelos países, instituições e universidades, destacando em sua ampla aceitação internacional da Declaração de Genebra, o Código Internacional de Ética Médica, o Código de Nuremberg e a Declaração de Helsinki promulgada pela Associação Médica Mundial, na segunda metade do século passado 23 .

A cirurgia, sem dúvida, é uma invasão e uma a agressão cruenta ao paciente, talvez uma das maiores demonstrações de como um paciente pode, literalmente, entregar a própria vida, nas mãos de um médico, depositando nele, toda a sua confiança. A cirurgia tem como objetivo principal a cura ou, pelo menos, a melhora do paciente, acreditando que, naquele momento, é a meIhor, se não a única opção terapêutica que permite, na medida do humanamente possível, proporcionar a cura de uma doença com uma atitude, um comportamento profissional consciente e ético ${ }^{24}$. 
O ético não deve estar apenas no procedimento, no ato cirúrgico propriamente dito ou no que acontece em uma sala de operação ou mesmo no exercício da cirurgia como especialidade. A ética deve estar na vida e conduta do cirurgião, de forma que todos os atos profissionais e de vida devam ser eticamente válidos, desde o estudo do paciente, a realização de estudos para a investigação diagnóstica, a informação do paciente, a obtenção do consentimento, o ato cirúrgico, os cuidados pós-operatórios, etc. Na cirurgia, as causas etiológicas (patologia cirúrgica) e efeitos (procedimento cirúrgico), culminam na invasão física e real pelo cirurgião, no corpo do paciente; é onde a relação médico-paciente adquire dimensões de alto impacto. O cirurgião é o único que aceita, de forma ética e responsável, a indicação inegável e necessária de uma cirurgia como resultado da sua capacidade profissional e de seu comportamento em relação ao paciente, familiares, colegas, seu meio e especialmente, consigo mesmo ${ }^{25}$.

O cirurgião não cuida apenas dos corpos humanos, trata de pacientes que são seres humanos. Estes procuram o cirurgião, porque eles estão sofrendo, sentindo, pensando e ainda vivenciam, com medo e tristeza, algo que ameaça à sua integridade. Eles têm limitações e impotência, buscam ajuda no cirurgião que deve estar preparado para fornecê-la. A ajuda deve ser prestada com atitudes e decisões com significado ético profundo, sem nunca esquecer do livre arbítrio do paciente, ao escolher um médico para resolver os seus problemas; na verdade, um cirurgião não pode nem deve falhar ${ }^{25}$.

A cirurgia é uma atividade intervencionista de diversas especialidades médicas, baseada no conhecimento, regida pelo raciocínio e executada com compaixão, paixão, perfeccionismo e bioética. Em sua prática, a satisfação e a felicidade do cirurgião projetam uma condição psíquica consoante com o exercício da virtude humana, e isso, de acordo com o preceito aristotélico, é a excelência da alma. Os dilemas atuais da bioética são oriundos do exercício inadequado da atividade cirúrgica, onde princípios como a distribuição justa dos recursos, a autonomia do paciente cirúrgico e a beneficência da cirurgia sobre a não maleficência foram resgatados, a fim de integrar o perfil atual do cirurgião virtuoso.

\section{rurgião}

\subsection{Os Quatro Gigantes da alma do ci-}

Todas as operações despertam na alma do cirurgião os "Quatro Gigantes" que desfilam no painel invisível da mente: a Morte, a Complicação, a Sequela e a Recidiva. É impossível afastar o trágico que assume o pensamento como vigilante; é o subjetivo que vive no recôndito do Psique, que adverte, conscientiza, torna o cirurgião responsável. Os Quatro Gigantes de aparecimento presuntivo acabam por se tornarem verdadeiros mandamentos da natureza ética pelo que representam como advertência e norma de cautela a ser seguida, independentemente de qualquer dificuldade ou contingência ligada à circunstânci- as temporárias ou ocasionais. Sem o terrível espectro da Morte, da Complicação, da Sequela e da Recidiva, seria impossível enfrentar as vicissitudes do difícil caminho do aperfeiçoamento e do domínio da doença com a finalidade da cura.

A lição de Claude Bernard, diz: "La vie c'est la mort", porque morremos a cada instante, à medida que nos aproximamos da morte. Tudo é feito para "estar na vida" como instinto de conservação da espécie ${ }^{26}$. Para os pacientes como Preceito Ético, conservar a vida é o dever do médico, que lhe impõe, como selo simbólico, o Juramento Hipocrático. O cirurgião sabe que o revés existe, o paciente que não admite, até porque Freud explica que a idéia da própria morte não tem acesso ao nosso inconsciente, só a morte dos outros é admitida. O revés não está no inconsciente do paciente, mas está no inconsciente do médico.

A conduta na adversidade é científica e técnica como comportamento, mas como atitude é acima de tudo Ética ${ }^{3}$.

\subsection{Os Fantasmas do Cirurgião}

O cirurgião depois do ato cirúrgico, passado o impacto do período da execução, tem com certa frequência, com uma descontinuidade que se extende pela continuidade de sua arte e de sua profissão o que é denominado de Fantasmas do Cirurgião. É que a cirurgia é Arte que se erige sobre a Ciência e que se transmuta em Técnica. Quando alcança os objetivos, fica acessível aos técnicos, vulgariza-se esquecida dos primórdios quando foi sobretudo Arte; é Técnica-Ciência-Arte que se pode atingir com a penetração no conhecimento e disciplina no exercício; é Técnica que se aplica ao corpo humano na intenção de restituir-lhe a harmonia perdida pelo desvio das normalidades e alteração das funções biológicas. Esta sempre sujeita às imperfeições do homem, ao erro essencial, ao erro verdadeiro, ao erro dos mortais. Para a nobre missão de tratar a vida humana em seus males, o importante é o comportamento diante do erro, a dignidade. A consciência do perigo eventual e do risco previsto está em permanente julgamento do próprio médico no espaço impenetrável de sua liberdade de confrontar o certo e o errado; é nele que a liberdade absoluta de julgar compõem o primeiro tribunal do ato médico. Tudo isso é íntimo e ético; o que sobra é a alternativa da Consciência Ética ou do Remorso com amargura. A Ética é o único padrão que independe de uma circunstância episódica que é moral social, temporal e mutável. O pensamento ético jamais poderá apartar-se de sua própria essência, espécie de superego, matizado pelas conveniências de cada um, mas presente e vigilante no comportamento geral e nas atitudes particulares.

Torna-se presente, na sua particularidade, na sua objetividade e na sua concretização em cada ato, mas originário inconfundível do geral, do subjetivo e do abstrato que são as formas essenciais que compõem a globalidade do que é Ético ${ }^{3}$. 


\section{4. ÉTICA MÉDICA VERSUS BIOÉTICA ?}

Todos os médicos têm conhecimento que a prática da medicina atual envolve muitos dilemas bioéticos, oriundos do desenvolvimento de novas tecnologias e novos procedimentos, que implicaram no surgimento de uma maior reflexão ética para tomada de qualquer decisão. É essencial, então, a presença da bioética no histórico escolar das Faculdades de Medicina, e a atualização de Bioética aos médicos praticantes ${ }^{27}$. Para aumentar a importância da bioética na prática diária da medicina, José Alberto Mainetti afirma justamente: "O caduceu, o estetoscópio e a dupla hélice do código da vida são símbolos da transformação e síntese da medicina em chave humanística. A concepção pós-moderna das chamadas ciências da arte da cura, apresentam um novo instrumento, o ethoscopio, o visor dos valores, para olhar o axiograma nas relações médico-paciente e da medicina social" 28

A Bioética como uma das muitas microéticas, tem uma série de éticas biomédicas alternativas coerentes com a visão ética que a sustenta, e, mesmo assim, são possíveis várias opções para os dilemas de acordo com seus princípios prioritários (autonomia, caridade, equidade etc.). O papel da bioética não é explicar e induzir comportamentos, mas esclarecer os fundamentos que aprovam ou não essas decisões e essas condutas ${ }^{21}$.

As bases da Bioética devem ser aplicadas para os problemas morais, que definem os seus limites que, certamente, não são econômicos nem legais. Se a bioética tivesse às abordagens técnicas, tais como o jurídico ou econômico, poderia estar limitada a aplicar mecanicamente o que está legislado, o que um juiz ordena, ou estar determinada pelas regras de uma política de saúde ou orçamentária ${ }^{29}$. Em ambos os casos, o médico estará livre de divergências, pois não tem opções selecionáveis. Se nos referirmos pontualmente a uma questão médica abordada a partir de uma base técnica, a noção de um diagnóstico de morte encefálica é definida, por décadas, por necessidade. De um ponto de vista, é certamente um problema técnico imediato, que se refere à metodologia aplicada para fazer um diagnóstico correto ou o critério adotado para sua definição, este pode ser considerado como a total ausência de atividade cerebral ou limitar-se ao tronco encefálico, a atividade cortical, etc. Desses dilemas, há muitas e diferentes posturas e fundamentações, mas o que é intrigante é a falta habitual,e nesse campo amplo de exceções justificadas, de motivos ético-biomédicas da necessidade obrigatória de diagnosticá-la16.

De qualquer maneira, o que deve ser o ponto fundamental das discussões bioéticas são os motivos para a necessidade de diagnosticar a morte encefálica, porque o dilema, neste caso, é na definição conceitual de presumíveis diferenças entre Indivíduo, Ser e Pessoa, tornando-se necessário propor uma análise mais profunda de várias visões filosóficas, na escolha entre quem sobrevive e quem morre, os fundamentos e as causas dessa seleção (e quem decide).

O objetivo teórico da Ética Biomédica, não é converter-se em um mediador de procedimentos, com um suporte cuja legitimidade está em discussão, mas não a sua legalidade, pois seria sustentada apenas pelas bases jurídicas. A bioética é teoricamente baseada na ética e deveria conter cada uma de nossas ações cotidianas, possuir uma escala de valores hierárquicos e, ter possibilidades para formular e decidir dilemas, sempre, e em princípio, com base na bondade ou maldade de cada ação, e não na sua conveniência22

Deste ponto de vista, não deve haver uma ética pragmática. No entanto, como é atualmente concebida, a Bioética parece manter uma dependência com a política, com a economia e com as políticas sanitárias mais com que a moral. Se a Bioética simplesmente limita-se a responder de forma mais ou menos mecânica aos dilemas, os converte simplesmente em fórmulas inflexíveis, em receitas.

Pelos grandes interesses, é evidente, que nada poderá impedir o auge da bioengenharia embrionária humana, e até a mesmo a clonagem; acredita-se que ninguém poderá deter a expansão deste processo, mas a pergunta que devemos formular neste âmbito é se a bioengenharia embrionária e a clonagem humana são atividades éticas. Por outro lado, se esses fatos não podem ser interrompidos, a Bioética deve impor modificações nos seus valores que justifiquem e permitam estes avanços tecnológicos. Até onde é necessário e se pode flexibilizar as regras e os valores humanos, e até que ponto fazê-los é moral?

\section{A B S T R A C T}

The professional practice of medicine today has a strong biological approach due to the increasing specialization of medical science. Often, science itself does not help to address and resolve a particular situation of a medical professional, and this is where human and social sciences, and especially other disciplines such as bioethics, can give a more humane and socialist approach, by systematically studying human behavior in the field of life and health sciences, considering moral values and principles. As part of this study, the segment that is limited to the analysis of ethical conflicts arising from the practice of medicine and patient care is known as medical ethics. Medical ethics, in the context of surgery, involves the integration of the surgical patient with the nature of the surgeon, influenced by his training and experience, his sensitivity to identify what is right. Ethics should not only be in the procedure, the surgery itself or in what happens in an operating room or even in the exercise of surgery as a specialty. Ethics must be in the life and conduct of the surgeon, so that all life and professional acts should be ethically valid.

Key words: Ethics, medical. Bioethics. Surgery. 


\section{REFERÊNCIAS}

1. Goldim JR. Rompendo os limites entre ciência e ética, Episteme, Porto Alegre, 2000.

2. Sousa Alves $\vee$ De. Bertrand Russell e a sua Crítica Analítica, Revista Portuguesa de Filosofia, 1972.

3. Queiroz J. Reflexões sobre Ética Médica, Gráfica MEC Editora Ltda., 2a ed., Rio de Janeiro, RJ, 2005.

4. Aristóteles. A Política, Ed. Martin Claret, 2001

5. Gracia D. Historia de la ética médica. Editorial Espasa- Calpe, Madrid, 1988

6. Chávez O. Hacia una mayor Humanización de la Medicina. Principios y Valores Éticos. Clemente Editores, Valencia-Venezuela, 2001

7. Maia $\mathrm{F}$ et al. Alguns Aspectos da Ética Médica e Científica. Cien Cult.Brasil, 1990.

8. Santo Agostinho. Cidade de Deus, Gulbenkian, Lisboa, 1991.

9. Maurer A. Filosofía Medieval. Emecé Editores, Buenos Aires-Barcelona, 1967.

10. Ochoa B. Ética y Ejercicio Profesional. Editorial Panapo, CaracasVenezuela, 1988

11. Minaré R. A preocupaçào de Van Rensselaer Potter, Parcerias Estratégicas, $n^{\circ} 16,2002$.

12. Garzón F. Experiencias en Bioética. Revista Colombiana de Filosofía de la Ciencia, Universidade do Bosque 2000; 1(2) y 3: 165-176.

13. Muñoz DR. Bioética: a mudança da postura ética, Revista Brasileira de Otorrinolaringologia, 2004

14. Reich WT. Encyclopedia of Bioethics. Free Press MacMillan, Nova York, 1978.

15. Drane JF. Origen y evolución de la bioética en Estados Unidos, Médico Interamericano, 1998.

16. Gracia D. Fundamentos de Bioética. Editorial EUDEMA S.A, Madrid, 1989.

17. Benatar S. Imperialism, research ethics and global health. J Med Ethics 1998;24(4):221.

18. Campbel A: Bioética Global: sonho ou pesadelo? O Mundo da Saúde 2000;22(6):366-369.

19. Whitehouse PJ. The ecomedical disconnection syndrome, The Hastings, 1999.
20. Comte-Sponville A : Petit Traité des grandes vertus, Presses Universitaires de France, 1995

21. Cely G: Una mirada bioética desde las ciencias. El Horizonte Bioético de las Ciencias. $5 a$ ed., Centro Editorial Javeriana (CEJA), BogotáColômbia, 2002.

22. Rivero S, Durante M. Ética en la medicina actual [Apresentação no Seminário El ejercicio actual de la medicina; 2007; Faculdade de Medicina. Universidade Nacional Autônoma do México, Méxi$\mathrm{co}$.

23. D'Allaines C: Historia de la Cirurgía. Edições Oikos-Tau S.A. BarceIona, 1971

24. Patiño J: Reflexiones sobre la Ética Quirúrgica a la Luz de la Ética Nicomaquea. Lecciones de Cirugía. 1ra ed. Editorial Médica Panamericana, Bogotá, 2001.

25. Torres F. Ética y Cirugía [Apresentação no Seminário El ejercicio actual de la medicina; 2002; Faculdade de Medicina. Universidade Nacional Autônoma do México, México].

26. Bernard C. An Introduction to the Study of Experimental Medicine, Macmillan \& Co, 1927.

27. Jonson A. The New Medicine and the Old Ethics. Harvard University Press, Cambridge, 1990.

28. Mainetti J. La transformación de la medicina. La Plata, Quirón, 1992.

29. Gonzalo MG. La responsabilidad del médico. Bioética y derecho. México: Fondo de cultura económica; 1999.

Recebido em 15/05/2011

Aceito para publicação em 28/07/2011

Conflito de interesse: nenhum

Fonte de financiamento: nenhuma

\section{Como citar este artigo:}

Antonio EMR, Fontes TMP. A ética sob o viés da bioética: o exercício moral da cirurgia. Rev Col Bras Cir. [periódico na Internet] 2011; 38(5). Disponível em URL: http://www.scielo.br/rcbc

Endereço para correspondência:

Eliana Maria Restum Antonio

E-mail: elianarestum@yahoo.com.br 